\title{
Electroplating moulds using dry film thick negative photoresist
}

\author{
E Kukharenka ${ }^{1}$, M M Farooqui ${ }^{1}$, L Grigore ${ }^{1}$, M Kraft ${ }^{1}$ \\ and N Hollinshead ${ }^{2}$ \\ ${ }^{1}$ Department of Electronics and Computer Science, University of Southampton, Highfield, \\ Southampton, SO17 1BJ, UK \\ ${ }^{2}$ Tecan Components Ltd, Tecan Way, Granby Industrial Estate, Weymouth, DT4 9TU, UK \\ E-mail: ak@ecs.soton.ac.uk and nickh@tecan.co.uk
}

Received 25 February 2003, in final form 17 April 2003

Published 13 June 2003

Online at stacks.iop.org/JMM/13/S67

\begin{abstract}
This paper reports on progress on the feasibility of fabricating moulds for electroplating using Ordyl P-50100 (negative) acrylate polymer based dry film photoresist, commercially available from Elga Europe

(http://www.elgaeurope.it). We used this photoresist as an alternative to SU8 negative epoxy based photoresist, which is very difficult to process and remove after electroplating (Lorenz et al 1998 Microelectron. Eng. 41/42 371-4, Eyre et al 1998 Proc. MEMS' 98 (Heidelberg) (Piscataway, NJ: IEEE) pp 218-22). Ordyl P-50100 is easy to work with and can be easily removed after processing. A single layer of Ordyl P-50100 was deposited by lamination up to $20 \mu \mathrm{m}$ thickness. Thicker layers (200 $\mu \mathrm{m}$ and more) can be achieved with multilayer lamination using a manual laminator. For our applications we found that Ordyl P-50100 dry film photoresist is a very good alternative to SU8 for the realization of $100 \mu \mathrm{m}$ high moulds. The results presented will open up new possibilities for low-cost LIGA-type processes for MEMS applications.
\end{abstract}

(Some figures in this article are in colour only in the electronic version)

\section{Introduction}

High-thickness photoresist lithography has been developed for a number of different MEMS applications. It has been used as a structural material, for fabricating complicated three-dimensional (3D) microstructures, moulds for metal electroplating and as packaging material $[4,5]$. Currently, a range of techniques exist to realize complex threedimensional microstructures, moulds for metal electroplating, and packaging material structures. Originally the $\mathrm{x}$-ray LIGA (Lithografie Galvanoformung Abformung) process was used to realize such structures. However, this technique involves considerable process complexity and high cost since a synchrotron radiation source is required. This motivated the search for cheaper and simpler methods to realize micromoulds. The two most promising alternative approaches are based on UV LIGA and deep reactive ion etching (DRIE).
This work reports recent advances in microfabrication techniques for high aspect ratio structures based on micromoulding and electroplating using dry film resist (acrylate based photopolymer). Dry film resist has numerous advantages such as: good conformability, excellent adhesion on any substrate, no liquid handling since there is no solvent, high process speed, excellent thickness uniformity over a whole wafer, simple handling, no formation of edge beads, low exposure energy, low cost, short processing time and nearvertical sidewalls $[6,7]$.

The dry film resist process offers the resist formulation as a very viscous ('dry') liquid, sandwiched between a polyolefin sheet and a polyester base, rolled up on a support core, cut or finished to various widths and roll lengths, as illustrated in figure 1. This photoresist was applied in the following way: the polyolefin sheet is removed prior to lamination of the resist on the substrate. Conformation is achieved by heating under pressure. The resist is then exposed to a standard UV 


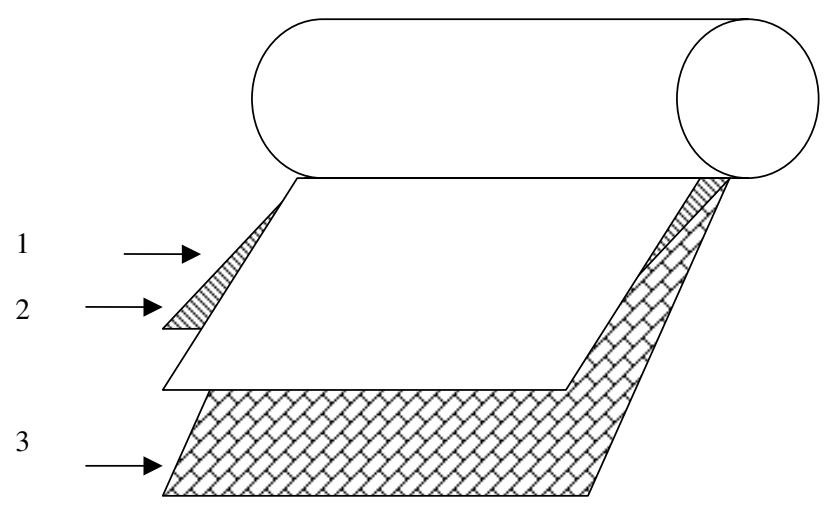

Figure 1. Three-layer structure of dry film photoresist. 1: polyethylene separation sheet; 2 : photoresist and 3: polyester support.

source. After lamination and exposure the polyester is peeled away.

There are different types of dry film photoresists widely used and commercially available, such as Riston ${ }^{\circledR}$ [8], Ordyl BF 410 [9], Etertec ${ }^{\circledR} 5600$ [10], DF 4615 [11], DFR-15 [12]. Riston ${ }^{\circledR}$ was already successfully used by Lorenz et al [6] for the fabrication of one- or multilevel, high-slope and highthickness electroplated microstructure.
In our work we used Ordyl P-50100, commercially available from Elga Europe. We used this photoresist to realize a micromachined disc for inertial sensing applications such as accelerometers and gyroscopes [13]. The disc is realized by electroplating into a mould of dry film photoresist.

\section{Process techniques for dry film photoresist}

The substrate wafer was prepared by a dehydration bake for $40 \mathrm{~min}$ at $140{ }^{\circ} \mathrm{C}$ and the substrates were cleaned in fuming nitric acid (FNA). In our work we used a hot roll laminator (Dynachem Manual Laminator/Cleaner 360), which requires manual loading, resist trimming and unloading. Since the resist is not diluted by a solvent a drying step is not needed. However, to make this dry layer conform to the substrate surface, heat and pressure are applied in a lamination step. The hot roll temperature is $130{ }^{\circ} \mathrm{C}$ for the upper roller and $120^{\circ} \mathrm{C}$ for the lower roller. The rollers are heated electrically, each one is independently thermostatically controlled. The hot roll pressure and lamination speed were 45 Psi and $52 \mathrm{~cm} \mathrm{~min}^{-1}$, respectively. The exposure was done with a contact mask using a Hybrid Technology Group (HTG) aligner with a UV light source (350-450 nm spectrum, mercury lamp) at 1.6$1.9 \mathrm{~mW} \mathrm{~cm}^{-2}$ intensity. As developer sodium carbonate $0.8-1.1 \% \mathrm{w} / \mathrm{w}$ was used with a processing temperature of

Bottom wafer fabrication

(a)

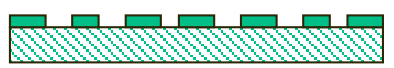

(c)

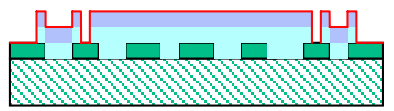

(e)

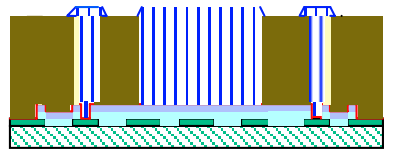

Top wafer fabrication

$(g)$

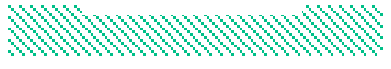

(h)

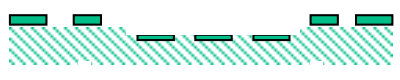

(i)

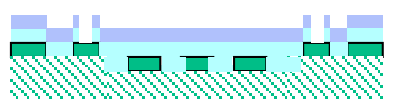

(b)

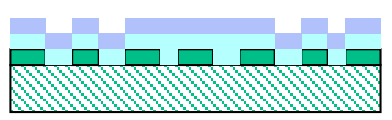

(d)

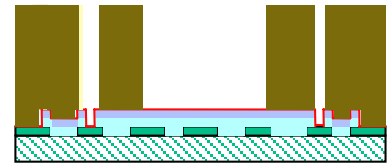

(f)

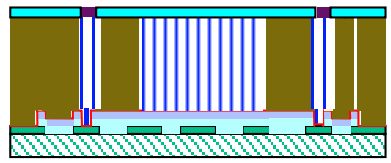

Wafer Assembly

(j)

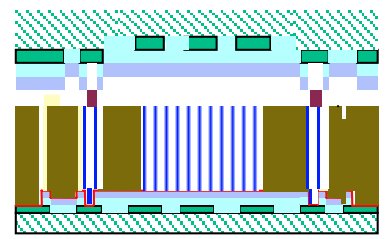

(k)

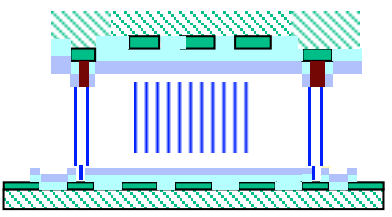

Silicon

$\mathrm{Cr}-\mathrm{Au}$

$\mathrm{Si}_{3} \mathrm{~N}_{4}$

$\mathrm{SiO}_{2}$

SU8/Ordyl P-50100

Nickel

Ordyl P-50100

$\mathrm{Pb}-\mathrm{Sn}$

Figure 2. Process of fabrication of Ni-levitated disc. $(a)-(f)$ : Bottom wafer fabrication. (a) Evaporation and patterning of Cr-Au; (b) $\mathrm{Si}_{3} \mathrm{~N}_{4}-\mathrm{SiO}_{2}$ PECVD deposition; (c) Au/Ti seed layer evaporation; (d) spinning of SU8/lamination Ordyl P-50100; (e) Ni electroplating; (f) PbSn electroplating. $(g)-(i)$ : Top wafer fabrication. $(g)$ Pyrex wet etch; $(h)$ evaporation and patterning of $\mathrm{Cr}-\mathrm{Au} ;(i) \mathrm{Si}_{3} \mathrm{~N}_{4}-\mathrm{SiO}_{2}$ etching. $(j)-(k)$ : Assembly. $(j)$ Alignment and reflow top and bottom electrodes; $(k)$ release of the Ni disc. 


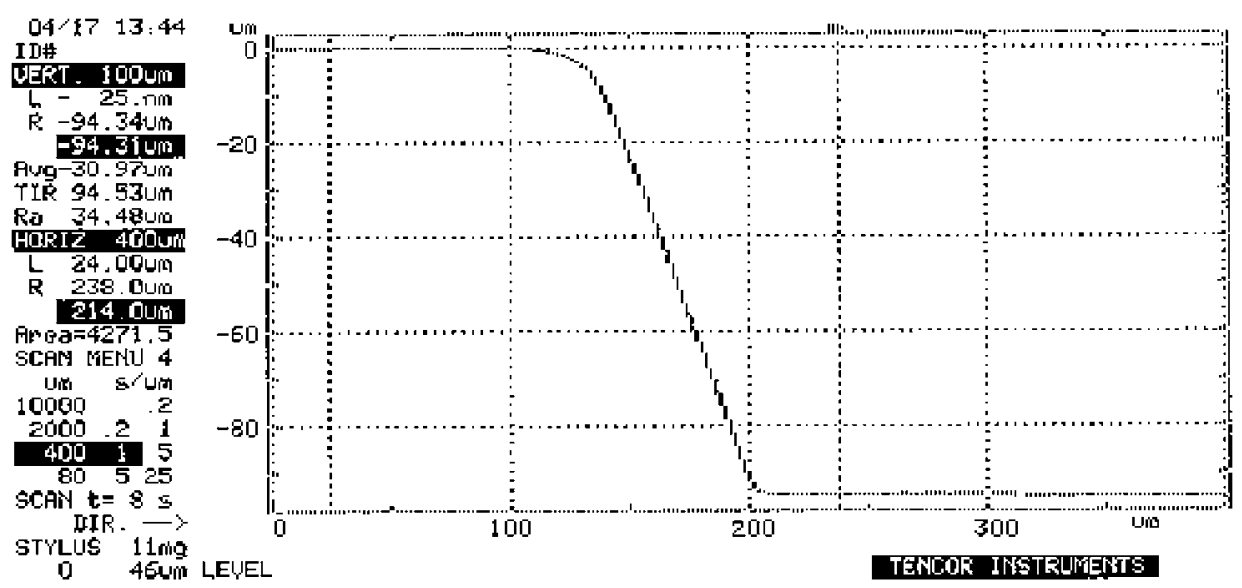

Figure 3. Deflection (micrometres) against position (micrometres) plot generated from the surface profiler for a $94 \mu \mathrm{m}$ mould.

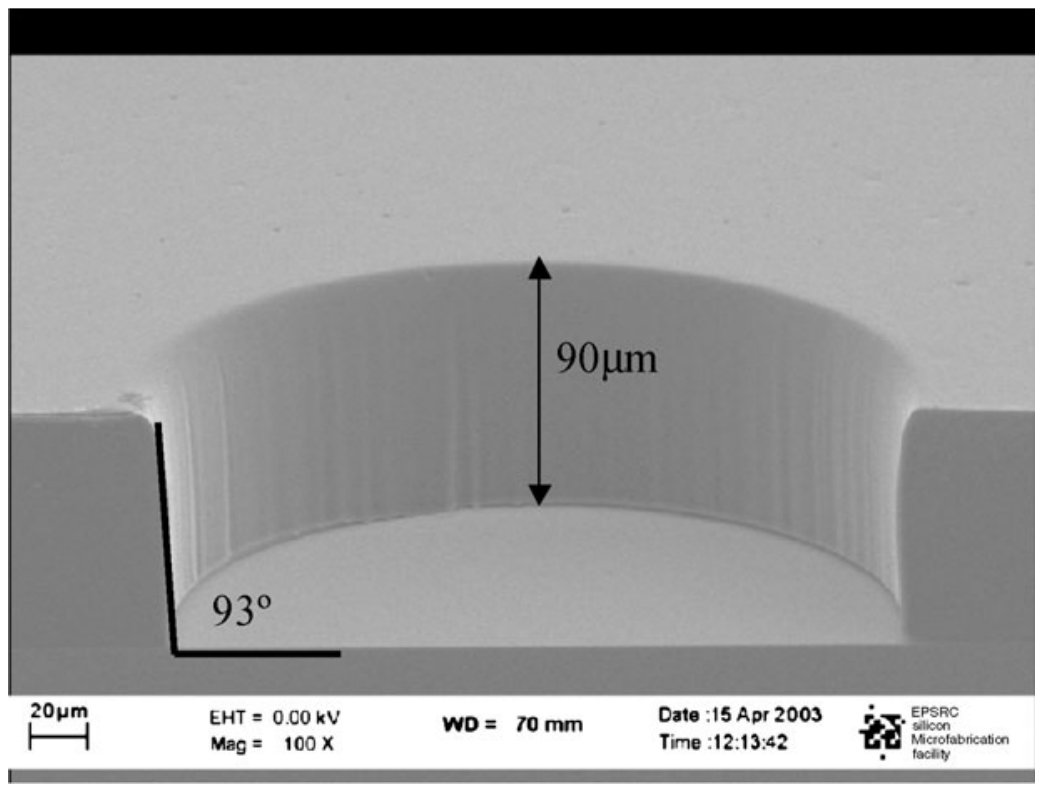

Figure 4. SEM image of $90 \mu \mathrm{m}$ thick mould in Ordyl P-50100.
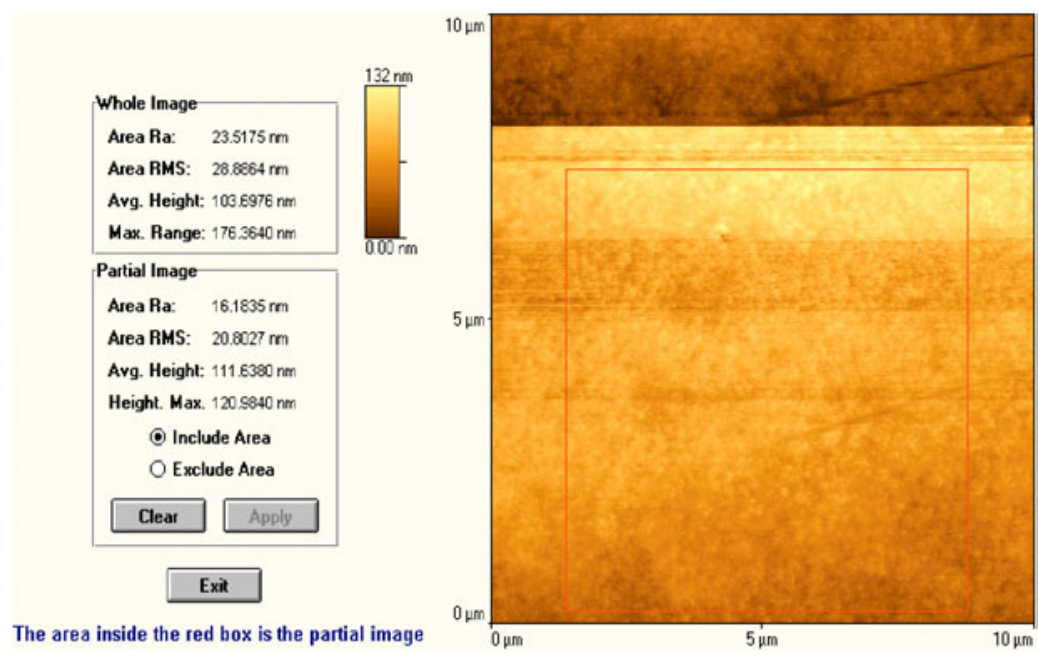

Figure 5. AFM topography showing a partial image of $8 \times 7 \mu \mathrm{m}^{2}$. 


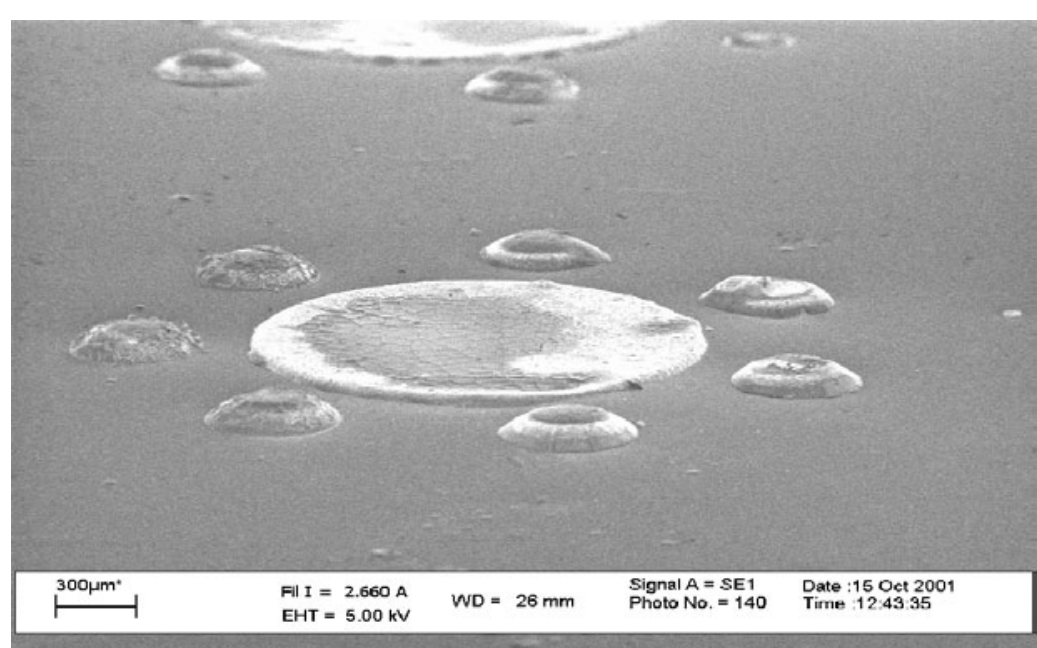

Figure 6. Ni-plated overgrowth structure.

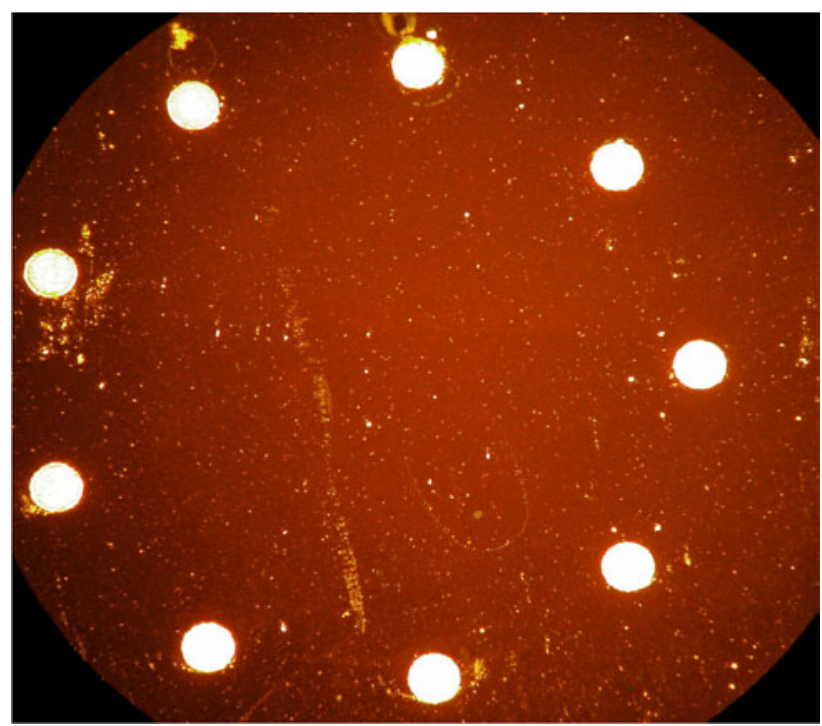

Figure 7. Microphotograph of tin-lead electroplated pillar microstructures.
$30{ }^{\circ} \mathrm{C}$ (tolerance $\pm 2{ }^{\circ} \mathrm{C}$ ). The developer was sprayed on the substrate with a pressure of 15-30 Psi. The stripper consists of sodium carbonate $10-30 \%$, sodium hydroxide $30-60 \%$ and disodium metasilicate $10-30 \%$ which is commercially available as 'Emphax Cleaner' from Canning.

\section{Fabrication process for a microdisc}

The fabrication of a micromachined disc for inertial sensing applications is currently under investigation. The disc will be levitated by electrostatic forces and hence has no mechanical connection to the substrate $[14,15]$. Consequently, it must be ensured by the fabrication process that the disc is completely freed. The disc itself consists of electroplated nickel. To mechanically restrain the disc when the system is powered down, it is encaged by electroplated pillars at the side and sets of electrodes on top and bottom.

A seven-mask process was developed to realize the design. Figure 2 shows a schematic diagram of the complete process flow.

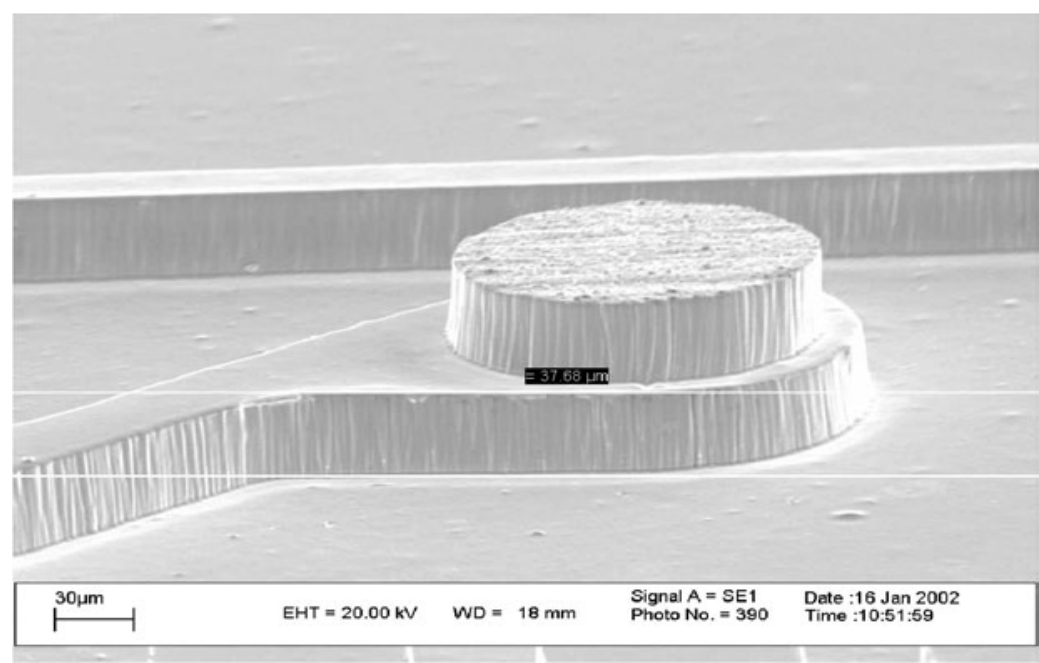

Figure 8. SEM picture of nickel shim double-level electroplated structures fabricated at Tecan Ltd. The height of both levels is $37 \mu \mathrm{m}$. 


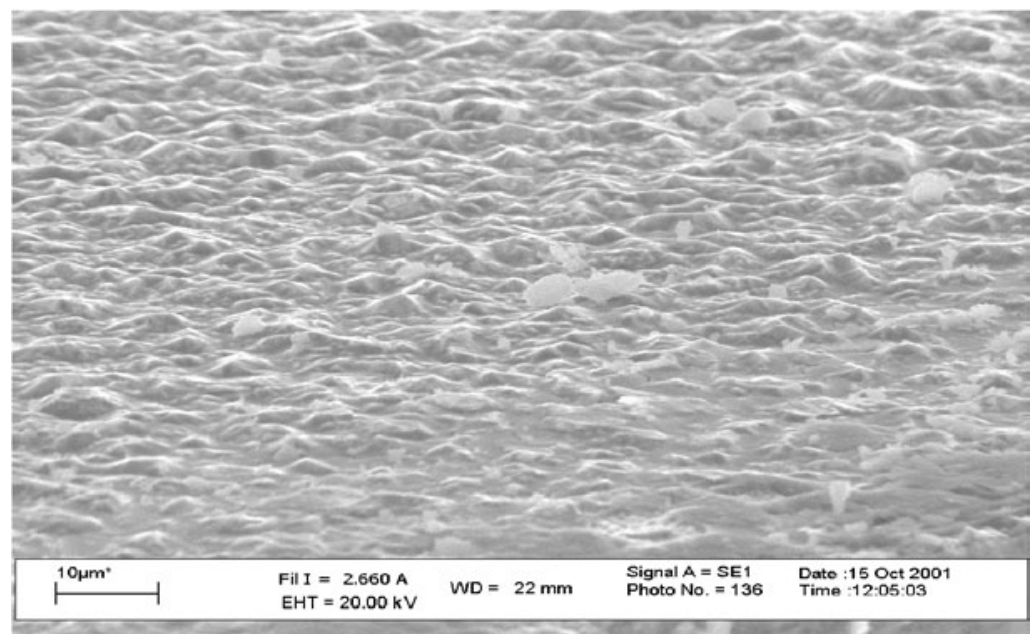

(a)

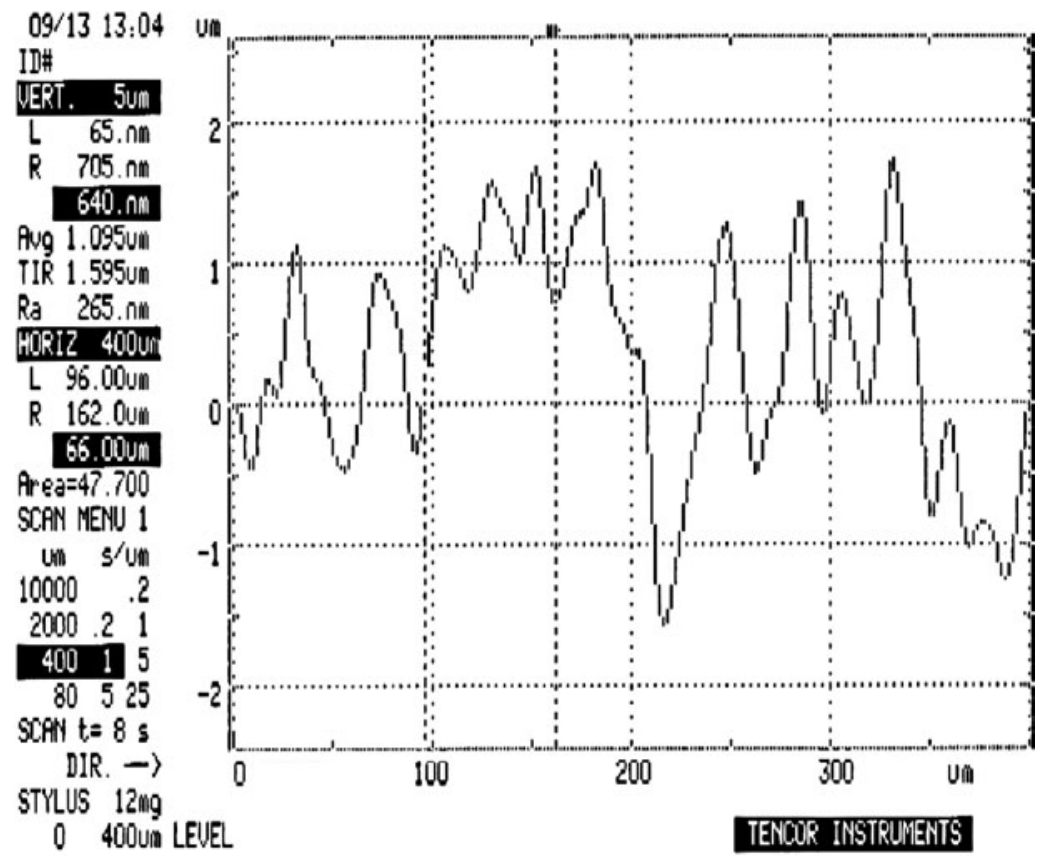

(b)

Figure 9. (a) SEM image of as-plated Ni structure exhibiting considerable surface roughness. (b) Alphastep profile indicating the roughness of Ni-plated surface.

The device will be fabricated by a process relying on electroplating Ni into a mould of thick dry film photoresist Ordyl P-50100. The assembled device consists of two Pyrex wafers on which the electrodes are fabricated and the disc electroplated. In the final step the wafers are bonded together.

The first step of the bottom wafer fabrication is to evaporate a $\mathrm{Cr}-\mathrm{Au}$ layer $(20 \mathrm{~nm} \mathrm{Cr}, 500 \mathrm{~nm} \mathrm{Au})$ on a Pyrex wafer. The thin $\mathrm{Au}$ and $\mathrm{Cr}$ will be photolithographically patterned and etched by an ion-beam etcher to form the bottom set of the electrodes, interconnections and the pads (figure 2(a)). Then, thin electrical insulating films of silicon nitride $\left(\mathrm{Si}_{3} \mathrm{~N}_{4}, 2000 \AA\right)$ and silicon dioxide $\left(\mathrm{SiO}_{2}, 3000 \AA\right)$ will be deposited by PECVD (figure 2(b)).
The $\mathrm{SiO}_{2}$ and $\mathrm{Si}_{3} \mathrm{~N}_{4}$ will be patterned and etched where the pillars will be electroplated. These pillars also provide the electrical connection to the top electrodes.

A thin film of $\mathrm{Au} / \mathrm{Ti}$ will then be evaporated to serve as a seed layer for electroplating $\mathrm{Ni}$ (figure $2(c)$ ). This will be followed by lamination of the Ordyl thick resist (figure $2(d)$ ), which can form layers up to 100-200 $\mu \mathrm{m}$. The Ordyl P-50100 will then be patterned defining moulds for the pillars and the disc. On the exposed areas of the Au seed layer $\mathrm{Ni}$ will be electroplated forming the pillars and the disc (figure 2(e)). It is very difficult to stop the plating at the right moment of time, consequently there will be formation of the so-called mushrooms. This will be removed by a lapping and polishing step. Next, dry film photoresist $(20 \mu \mathrm{m})$ will be laminated and 


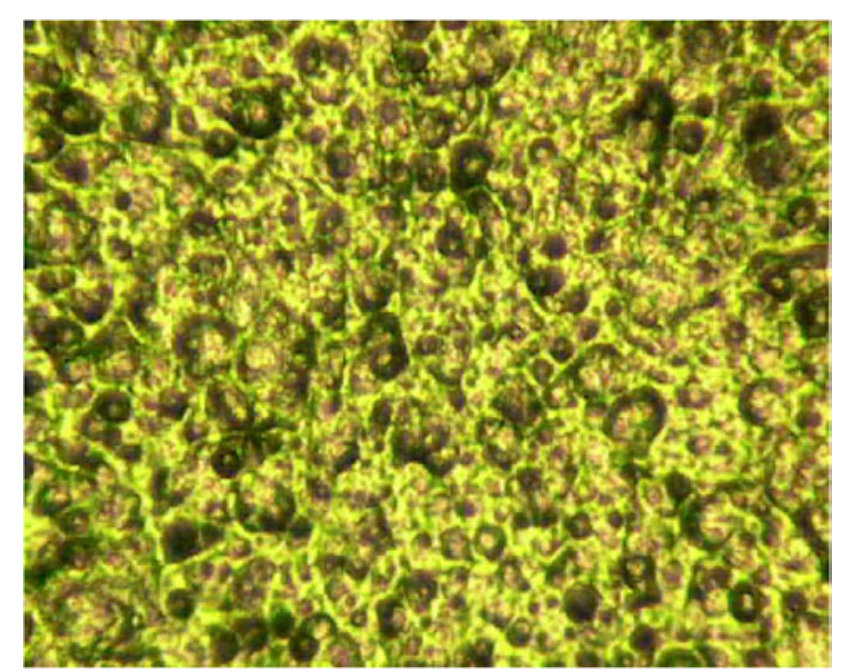

(a)

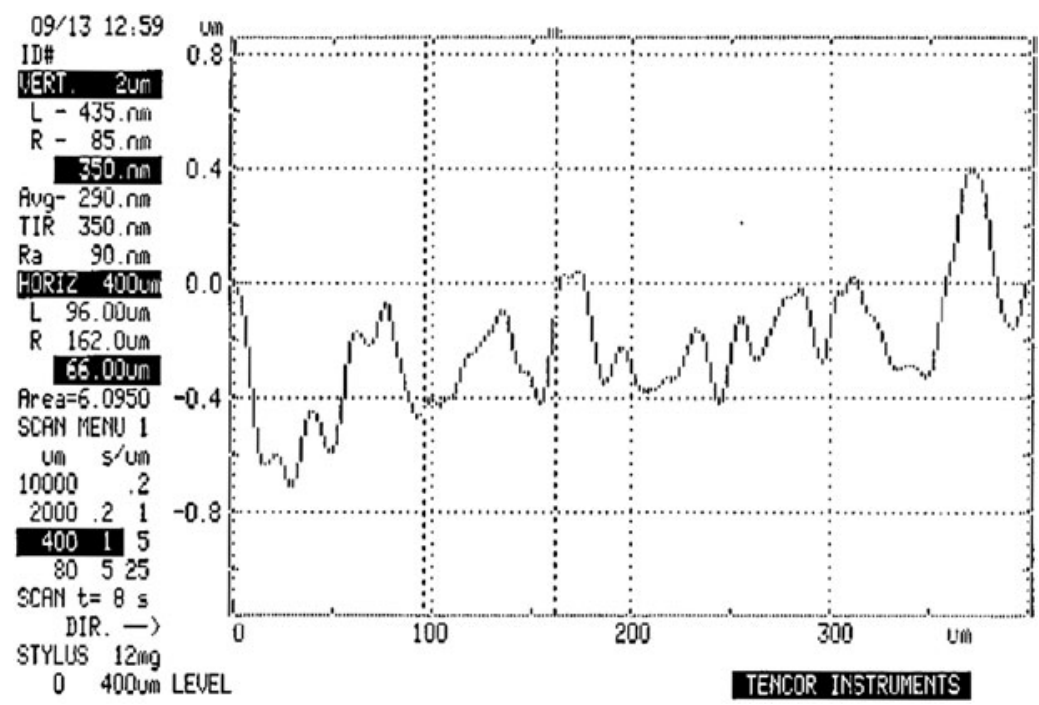

(b)

Figure 10. (a) Ni surface after lapping with $3 \mu \mathrm{m} \mathrm{Al}{ }_{2} \mathrm{O}_{3}$ for $1 \mathrm{~h}$. (b) Alphastep profile indicating the roughness of Ni-plated surface after lapping.

patterned with the fourth mask for the pillars and a thin layer of $\mathrm{PbSn}$ will be electroplated (figure $2(f)$ ). This concludes the processing of the bottom electrode wafer.

For the top wafer fabrication, a standard photoresist will be patterned with the first mask to define a gap between the disc and electrodes (figure $2(g)$ ). Next, a Cr-Au layer $(20 \mathrm{~nm} \mathrm{Cr}$, $500 \mathrm{~nm} \mathrm{Au}$ ) will be evaporated and patterned to define the top set electrodes (figure 2(h)). Then $\mathrm{Si}_{3} \mathrm{~N}_{4}(2000 \AA)$ and $\mathrm{SiO}_{2}$ (3000 $\AA$ ) will be deposited by PECVD. The $\mathrm{SiO}_{2}$ and $\mathrm{Si}_{3} \mathrm{~N}_{4}$ will be patterned to define electrical contact with the bottom electrodes (figure 2(i)). Next, the top and bottom wafers will be assembled by flip-chip bonding. Finally, the two wafers will be bonded together by reflow of $\mathrm{PbSn}$ (figure $2(j)$ ). This provides an automatic self-alignment of the two wafers due to surface tension. The top wafer will be sawn, the Ordyl P-50100 will be stripped using 'Emphax Cleaner', without damaging the electroplated structure. Next, the bottom electrodes will be sawn and the gold used as seed layer will be etched. This will free the disc (figure $2(k)$ ).
The masks contain arrays of varying geometries for disc diameter from $800 \mu \mathrm{m}$ to $4 \mathrm{~mm}$, disc thickness 100-200 $\mu \mathrm{m}$ and disc-electrode gap 2-4 $\mu \mathrm{m}$.

\section{Results}

\subsection{Mould formation}

As an experimental process 20, 90 and $100 \mu \mathrm{m}$ Ordyl P-50100 moulds for electroplating by single lamination were investigated. The Alphastep surface profiler shows the thickness measurement and profile in figure 3 .

Table 1 shows the optimized results of the lamination, exposure and development process for the dry film photoresist used. Figure 4 shows the SEM pictures of a $90 \mu \mathrm{m}$ thick mould. We achieved very good verticality of sidewalls. The slope of the sidewall corresponds to an angle of $93^{\circ}$, which is a typical value for this photoresist. The sidewall profiles indicate very good dimensional control over the entire resist thickness. Several measurements were made in different areas 


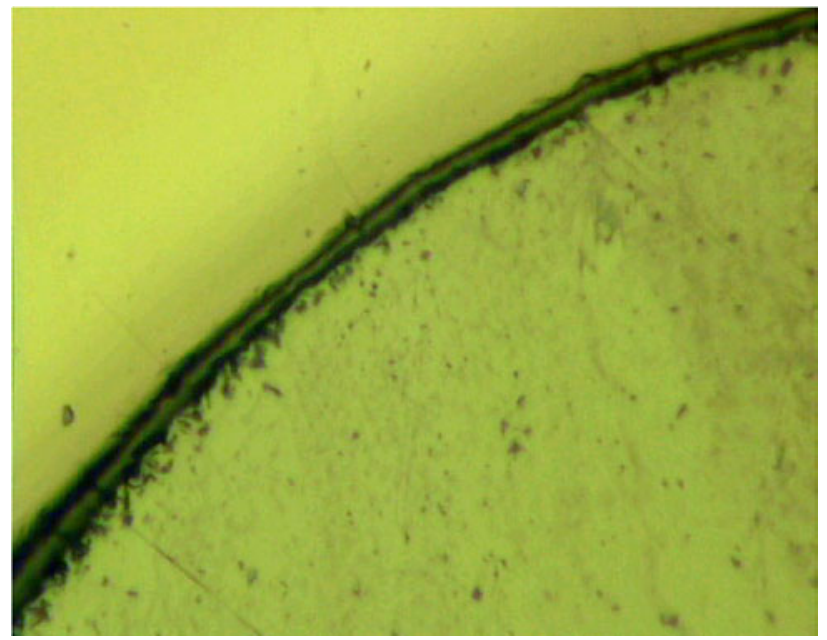

(a)

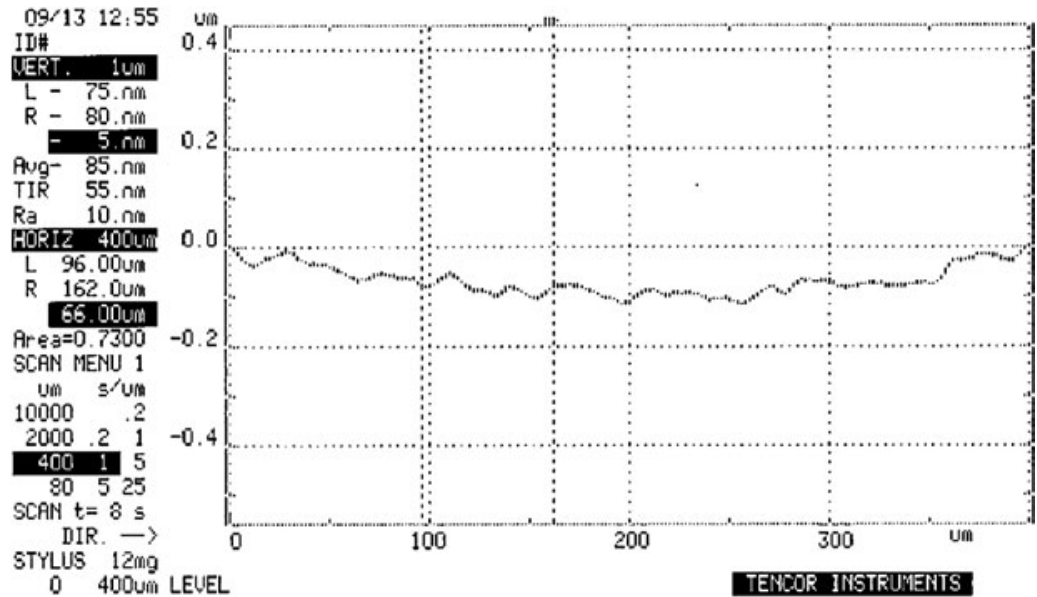

(b)

Figure 11. (a) Ni surface after polishing by Syton (SF1) for 2 h. (b) Alphastep profile indicating the roughness of Ni-plated surface after polishing.

Table 1. Optimized values of exposure and development time for Ordyl P-50100 thick negative photoresist.

\begin{tabular}{|c|c|c|c|}
\hline Parameters & $\begin{array}{l}\text { One layer, } \\
20 \mu \mathrm{m} \text { Ordyl P-50100 }\end{array}$ & $\begin{array}{l}\text { One layer, } \\
100 \mu \mathrm{m} \text { Ordyl P-50100 }\end{array}$ & $\begin{array}{l}\text { Two layers, } \\
200 \mu \mathrm{m} \text { Ordyl P-50100 }\end{array}$ \\
\hline Exposure & $40 \mathrm{~s}$ & $60-80 \mathrm{~s}$ & $300-350 \mathrm{~s}$ under optimization \\
\hline Development time & $130 \mathrm{~s}$ & $320 \mathrm{~s}$ & $640 \mathrm{~s}$ \\
\hline
\end{tabular}

of each wafer in order to check the thickness uniformity, which was within a few microns. In order to obtain an SEM cross section, the wafers were cleaved through the centre of the moulds. Figure 5 shows an AFM picture of a surface area of $100 \mu \mathrm{m}^{2}$ of the photoresist. According to this image the RMS surface roughness is about $20 \mathrm{~nm}$, which indicates the absence of pinholes. Consequently, this resist is very suitable for stacking of multiple layers and opens possibilities for a multilevel electroplating process.

\subsection{Electroplating}

Nickel was electroplated into one- and two-level photoresist moulds. A nickel sulphamate electrolyte solution was used for electroplating with a current density of $18 \mathrm{~A} \mathrm{dm}^{-2}$, and a deposition rate of $4 \mu \mathrm{m} \mathrm{h}^{-1}$ for single-level electroplated structure. A dc power supply was used. Table 2 lists the composition of such a solution and operation conditions. Figure 6 shows the SEM picture of Ni-electroplated structure into $100 \mu \mathrm{m}$ of dry film photoresist. An overgrowth structure was observed.

For the fabrication of a levitated disc PbSn electroplated pillars are required. Figure 7 shows a microphotograph of the top view of pillars taken under an optical microscope. We used tin-lead fluoborate electroplating solution. The composition of the plating bath and operation conditions are given in table 3. The deposition rate was between 3 and $5 \mu \mathrm{m} \mathrm{h}^{-1}$. This electroplating was easy to realize in an ordinary beaker at room temperature with mild agitation. 
Table 2. Composition of sulphamate electroplating solution and operating conditions.

\begin{tabular}{lc}
\hline Component & Concentration $\left(\mathrm{g} \mathrm{l}^{-1}\right)$ \\
\hline Nickel sulfamate, $\mathrm{Ni}^{-}\left(\mathrm{NH}_{2} \mathrm{SO}_{3}\right)_{2}$ & 300 \\
Nickel chloride, $\mathrm{NiCl}_{2} \cdot 6 \mathrm{H}_{2} \mathrm{O}$ & 6 \\
Boric acid, $\mathrm{H}_{3} \mathrm{BO} \mathrm{O}_{3}$ & 30 \\
\multicolumn{3}{c}{ Operating conditions } \\
Temperature $\left({ }^{\circ} \mathrm{C}\right)$ & 55 \\
Cathode current density $\left(\mathrm{A} \mathrm{dm}^{-2}\right)$ & $2-25$ \\
Agitation & Air agitation \\
\hline
\end{tabular}

Table 3. Composition of tin-lead electroplating solution.

\begin{tabular}{|c|c|}
\hline Component & Concentration $\left(\mathrm{g}^{-1}\right)$ \\
\hline Tin $\left(\mathrm{Sn}^{2+}\right)$ fluoborate & $12-20$ \\
\hline Lead $\left(\mathrm{Pb}^{2+}\right)$ fluoborate & $8-14$ \\
\hline Peptone, industrial & $2-7$ \\
\hline $\mathrm{HBF}_{4}$, fluoboric acid & $350-500$ \\
\hline \multicolumn{2}{|c|}{ Operating conditions } \\
\hline Temperature $\left({ }^{\circ} \mathrm{C}\right)$ & $25-27$ \\
\hline Cathode current density $\left(\mathrm{A} \mathrm{dm}^{-2}\right)$ & $1.07-2.69$ \\
\hline Agitation & Mild \\
\hline
\end{tabular}

As a further application of Ordyl P-50100 a multiplayer electroplated structure is realized. Figure 8 shows an example of a two-level electroplated structure demonstrating the feasibility of multilevel electroplating process using Ordyl P-50100. In this case nickel sulphamate electrolyte solution was used. The dc current density was $3.5 \mathrm{~A} \mathrm{dm}^{-2}$ which resulted in a deposition rate of $35.8 \mu \mathrm{m} \mathrm{h}^{-1}$. This type of multilayered structure has numerous applications for microreplicated products, such as mesh and sieve products, optical encoders, laser slits, fine tolerance gaskets and shims.

\subsection{Polishing}

The raw Ni surface after electroplating was very rough. The SEM picture in figure $9(a)$ shows the surface of Ni-plated structure. The surface roughness, which is 4-6 $\mu \mathrm{m}$, was measured by a surface profilometer and is shown in figure $9(b)$. The smoothness of the surface is insufficient for fabrication of the levitated disc. For this reason, the lapping and polishing steps were necessary.

Figure 10 shows a micrograph taken under optical microscope after lapping for $1 \mathrm{~h}$ with $3 \mu \mathrm{m} \mathrm{Al}_{2} \mathrm{O}_{3}$. However, the surface was still very rough. In order to achieve good surface quality, a final polishing by Syton (SF1) for $2 \mathrm{~h}$ was done. Figure 11 shows a microphotograph of the surface with a roughness of $0.2 \mu \mathrm{m}$, which is sufficient for our applications.

\section{Conclusions}

We have presented optimized results of process flow relating to Ordyl P-50100 dry film negative photoresist for 20 and $90 \mu \mathrm{m}$ thickness. We demonstrated that Ordyl P-50100 dry film resist is a promising photoresist for realization of high-thickness moulds for MEMS applications. The surface analysis showed that this photoresist is suitable for multilevel structures. We found that Ordyl P-50100 has an excellent thickness uniformity over a whole wafer and near-vertical sidewalls The short processing time is relatively short and it is easy to remove. This photoresist is a very promising fabrication process for a levitated disc currently under investigation.

Further work will be done on the optimization of the resist process parameters, which will yield layers of Ordyl P-50100 of more than $200 \mu \mathrm{m}$ thickness. Optimizing the electroplating conditions will improve the surface quality of the electroplated Ni structures.

\section{References}

[1] http://www.elgaeurope.it

[2] Lorenz H, Laudon M and Renaud P 1998 Mechanical characterization of a new high-aspect-ratio near UV-photoresist Microelectron. Eng. 41/42 371-4

[3] Eyre B, Blosiu J and Wiberg D 1998 Taguchi optimization for processing EPON SU8 resist Proc. MEMS'98 (Heidelberg) (Piscataway, NJ: IEEE) pp 218-22

[4] Dellmann L, Roth S, Beuret C, Racine G-A and Lorenz H Fabrication process of high-aspect ratio elastic structures for piezoelectric motor applications Proc. Transducer's 97 (Chicago) pp 641-7

[5] Guerin L, Torosdagi A, Eichenberger P and Renaud P 1998 High aspect ratio planar coils embedded in SU8 photoepoxy for MEMS applications Proc. Eurosensors, Eurosensors XII (Southampton) pp 11-13

[6] Lorenz H et al 1996 Low-cost technology for multiplayer electroplated parts using laminated dry film resist Sensors Actuators A 53 364-8

[7] Dietz K H 2001 Dry Film Photoresist Processing Technology (Research Triangle Park, NC: Electrochemical Publications Ltd) $\mathrm{p} 432$

[8] http://www.Dupont.com/pcm

[9] http://www.tok.co.jp/products/products-e2.htm

[10] http://www.insulectro.com/dryfilm.htm

[11] http://www.thinktink.com/stack/volumes/voli/store/specs/ 4615 spec.htm

[12] http://www.jsits.com/kpr/facility.htm

[13] Kraft M 2000 Micromachined inertial sensors: the state-ofthe-art and a look into the future Meas. Control $\mathbf{3 3}$ $164-8$

[14] Houlihan R and Kraft M 2002 Modelling of an accelerometer based on a levitated proof mass J. Micromech. Microeng. 12 495-503

[15] Kraft M, Farooqui M M and Evans A G R 2001 Modelling and design of an electrostatically levitated disc for inertial sensing applications J. Micromech. Microeng. 11 423-7 